\title{
Computational fluid dynamics study of dusty air flow over NACA 63415 airfoil for wind turbine applications
}

\begin{abstract}
Gulf and South African countries have enormous potential for wind energy. However, the emergence of sand storms in this region postulates performance and reliability challenges on wind turbines. This study investigates the effects of debris flow on wind turbine blade performance. In this paper, twodimensional incompressible Navier-Stokes equations and the transition SST turbulence model are used to analyze the aerodynamic performance of NACA 63415 airfoil under clean and sandy conditions. The numerical simulation of the airfoil under clean surface condition is performed at Reynolds number $460 \times 10^{3}$, and the numerical results have a good consistency with the experimental data. The Discrete Phase Model has been used to investigate the role sand particles play in the aerodynamic performance degradation. The pressure and lift coefficients of the airfoil have been computed under different sand particles flow rates. The performance of the airfoil under different angle of attacks has been studied. Results showed that the blade lift coefficient can deteriorate by $28 \%$ in conditions relevant to the Gulf and South African countries sand storms. As a result, the numerical simulation method has been verified to be economically available for accurate estimation of the sand particles effect on the wind turbine blades.
\end{abstract}

\subsection{INTRODUCTION}

Renewable energy resources are the primary contributors to achieve sustainable energy production. Energy crisis, climate changes such as atmosphere temperature rise due to the increase of greenhouse gases emission and the Kyoto Protocol restrictions in generation of these gases, coupled with high oil prices, limitation and depletion of fossil fuels reserves make renewable energies more noticeable. Among the renewable energy resources, wind energy has had the fastest growth in the world[1]. For Instance, India showed a significant development in the wind power industry in Asia in the previous years with capacities of $35071 \mathrm{MW}$. In addition, the Egyptian wind energy capacity is estimated to be increased to 7,200 MW by 2020 [2].

The previous research studies evaluated the degradation of the airfoil performance due to several parameters and conditions, such as roughness type, accumulation height, accumulation location and angle of attack. Most simulation studies were performed at Reynolds number range between $1 \times 10^{3}$ and $1 \times 10^{6}$. The primary performance measures studied were the surface lift and drag coefficients.

According to Zidane et al [2], researchers have extensively concentrated on ice accumulation studies and its effect on the aerodynamic properties of the airfoils. The aerodynamic performance of the wind turbine blades in the sandy environment such as the Gulf and South African countries is still incomplete. Deshun et al.[3], Nianxin[4] and Salem et al. [5]are examples from the few studies which presented the effect of sandy environment on the aerodynamic performance of the wind turbine blade using a 2D incompressible SST $k-\omega$ turbulence model. They used a DU 95-W-180 NACA 63-430 and NACA 63215 airfoil designs respectively. The CFD models of Deshun et al.[3] and Nianxin [4] were validated using the wind tunnel experimental data under a clean environment conditions. Salem et al. [5]validated the 
numerical results obtained by Nianxin [4]and compared it with Khalfallah and Koliubb[6]. Reynolds number that was used is $3 \times 10^{6}, 1.6 \times 10^{6}$ and $1 \times 10^{6}$ respectively. Nianxin [4] and Deshun et al. [3]concluded that the lift and drag coefficients are affected by small surface roughness height. In addition, the surface roughness results turbulence and flow separation. However, Salem et al. [5]concluded that accumulation of dust on the wind turbine blade causes a sever loss in the wind power generated. Ferrer and Munduate [7] used CFD and Xfoil to study the aerodynamic properties of a 2D S814 airfoil design with surface roughness at the airfoil leading edge. The simulated surface roughness represented the airfoil contamination by bugs, dirt or debris. The numerical results were validated by experimental measurements of NREL S814. They claimed that CFD provides a good prediction for the surface roughness phenomenon, but, Xfoil fails to

estimate the roughness effect in the case of fully turbulent flow. Finally, they concluded that surface roughness could negatively affect the aerodynamic performance of the airfoil.

This paper studies the change of the aerodynamic performance of NACA 63415 airfoil due to the sand particles hitting at the leading edge. Thus, the wind turbine designers have the ability to estimate loads and power losses for wind turbines operating in dusty environments.

\subsection{Methodology}

\subsection{Governing Equations}

The flow around NACA 63415 was simulated by the RANS Navier-Stokes equation for two-dimensional, viscous, incompressible flow. The continuous equation and Momentum equation based on RANS N-S equations are as shown in eq. (1) and eq. (2):

$\frac{\partial u_{\mathrm{i}}}{\partial x_{\mathrm{i}}}=0$

$\rho(\nabla . \mathrm{V}) \mathrm{V}=-\nabla p+\nabla 2 V-\overline{\rho u \iota^{\prime} u \jmath^{\prime}}$

\subsection{Turbulence Model}

Using the CFD software Fluent, the 2D NACA 63415 aerodynamic characteristics were simulated numerically. The control equations were Navier-Stokes equations, and four turbulence models were applied: Standard $k-\epsilon$ model of two equations [8], RNG $k-\epsilon$ model of two equations[9], SST $k-\omega$ of two equations[10] and Transition SST model [11] of four equations. Coupled algorithm was used to solve the coupling problem between velocity components and pressure in momentum equations. Turbulence kinetic energy was taken as third-order MUSCL scheme in Calculation. However, momentum and specific dissipation rate were solved using second-order upwind scheme.

\subsection{Discrete Phase Modeling}

It consists of spherical particles, which introduces the sand particles in the continuous phase. The force balance equates the particle inertia with the forces acting on the particle, and can be written shown in eq. (3) and eq. (4):

$\frac{d U_{p}}{d t}+F_{d}\left(U-U_{P}\right)+\frac{g_{x}\left(\rho_{p}-\rho\right)}{\rho_{p}}+F_{x}$

$F_{d}=\frac{18 \mu C_{d} R e_{p}}{\rho_{p} d_{p}^{2} 24}$

where, $U_{p}$ is the particle velocity, $F_{d}\left(U-U_{p}\right)$ is the drag force per unit particle mass, $F_{x}$ is an additional acceleration term, $U$ is the relative speed between airfoil and flow, $\mu$ is the fluid dynamic viscosity 
coefficient, $\rho$ is the air density, $\rho_{p}$ is the density of the sand particle, $d_{p}$ is the sand particle diameter, $R e_{p}$ is the relative Reynolds number for the sand particle[12].

\subsection{Mesh Dependence Investigation}

The computational zone consists of a semicircle with the radius of $12.5 \mathrm{~m}$ and a rectangle with the length of $25 \mathrm{~m}$. The chord length of NACA 63415 is $1 \mathrm{~m}$. The airfoil is located nearly to the semicircle center. This is shown in Figure 1. The grid nodes are 120,878, while, the grid height near the airfoil surface is 7 $x 10^{-6} \mathrm{~m}$ as shown in Figure 2. The flow was assumed to be steady with free stream velocity giving a Reynolds number of $460 \times 10^{3}$. The range of values of the dimensionless wall distance $Y$ plus $\left(Y^{+}\right)$through the wind turbine blade airfoil were less than 1.

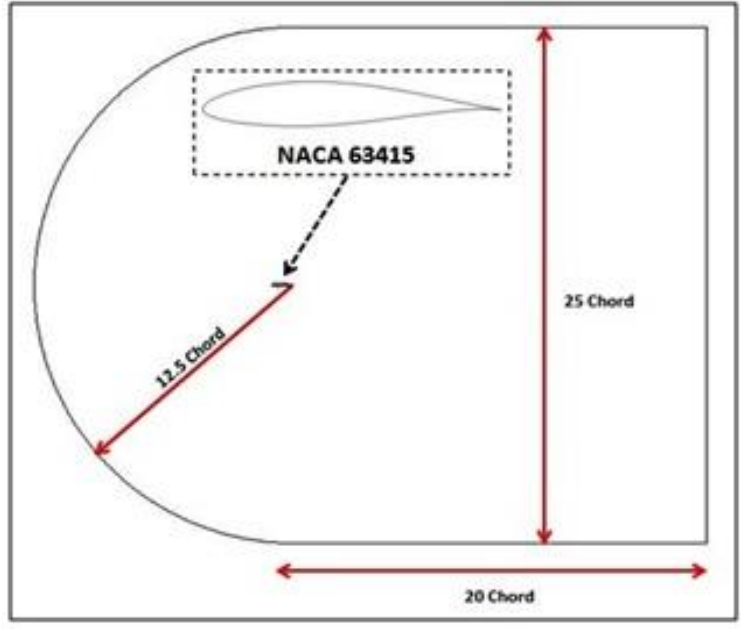

Figure $1 \mathrm{C}-\mathrm{H}$ Computational Domain

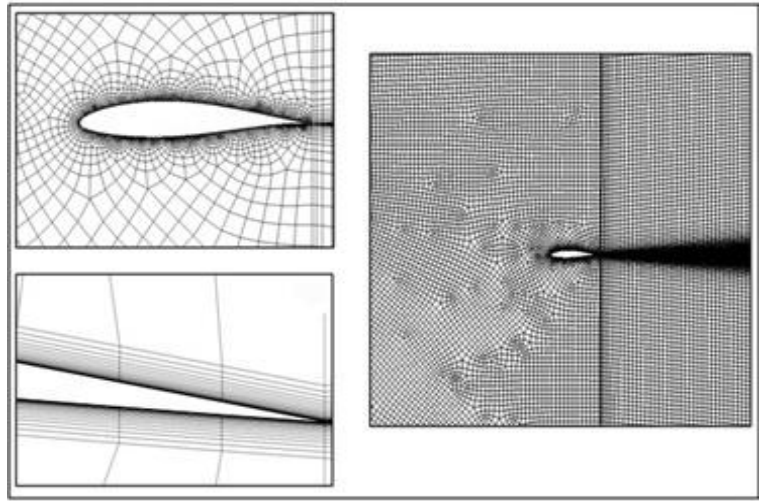

Figure 2 General Mesh with Boundary Adaptation

\subsection{Results and Discussion}

\subsection{Numerical Simulation under Clean Surface Condition}

The numerical simulation under clean airfoil surface condition was made to compare with the wind tunnel experimental data taken from Bak et al [13] to ensure that the numerical model is available for the freestream flow past the airfoil. The experiment was performed at Reynolds number $1.6 \times 10^{6}$. The lift and pressure coefficients of the NACA 63415 airfoil were computed under the angle of attack between 0 and 10 degree. The calculation results of Transition SST model were closest with the experimental data. The comparison between numerical results and experimental data is shown in figures 3, 4, 5 and 6 . Figure 3 
presents the lift coefficient variation with the angle of attack. However, figures 4,5 and 6 present the pressure distribution along the chord length of the airfoil at different angle of attacks. As can be seen in the figures, the larger angle of attack, the greater difference of pressure coefficient between suction side and pressure side. It was obvious that the numerical results had a good consistency with the experimental data, except for small discrepancies in the pressure coefficient curves for both the lower and upper parts of the airfoil. Then, in the following of the paper, the numerical simulation model could be used to investigate the sand effect on the airfoil.

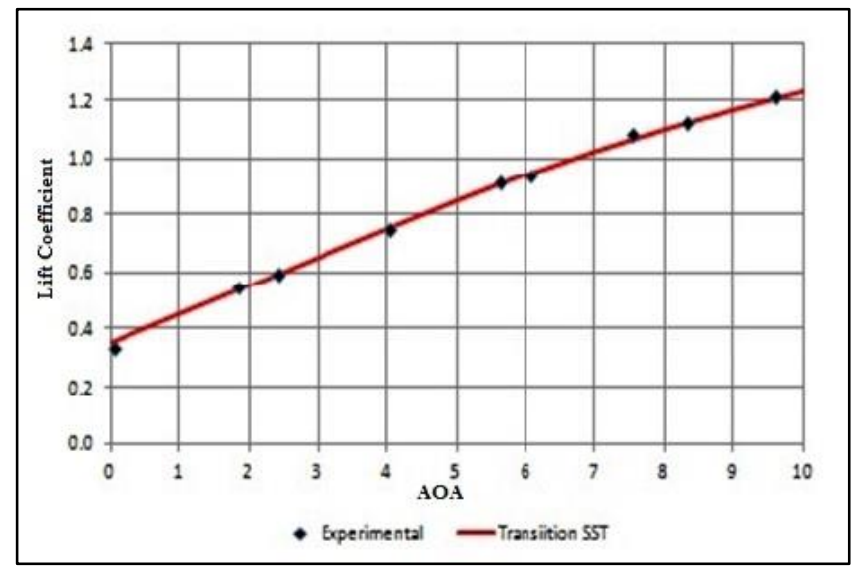

Figure 3 Validation of Lift Coefficient at Different Angles of Attacks

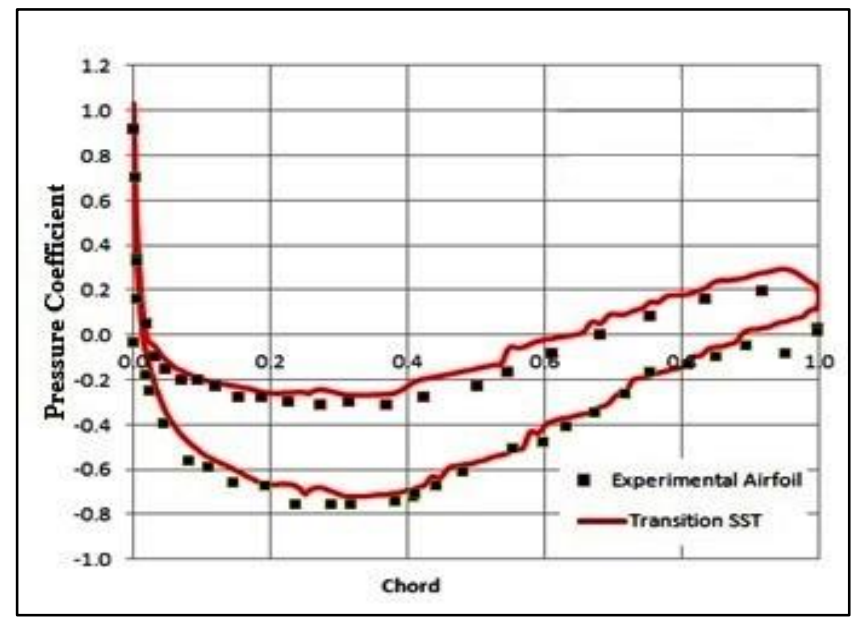

Figure 4 Validation of Pressure Coefficient at AOA $0^{\circ}$

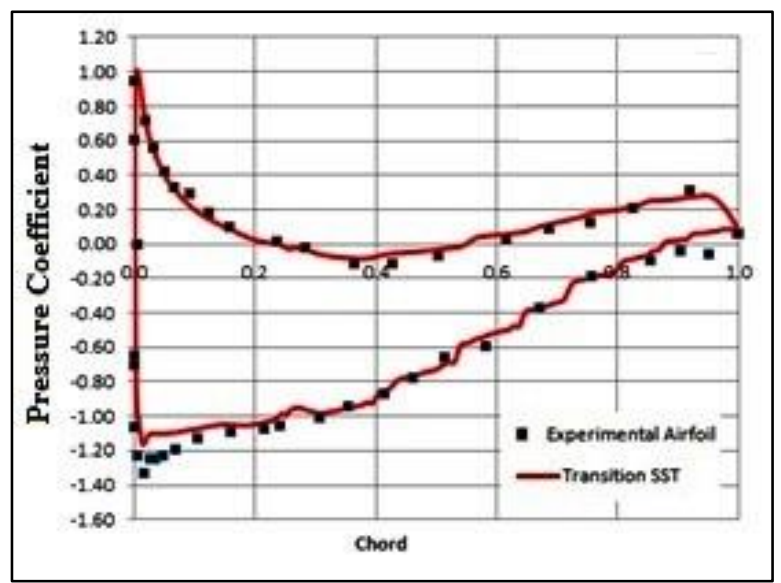


Figure 5 Validation of Pressure Coefficient at AOA $4^{\circ}$

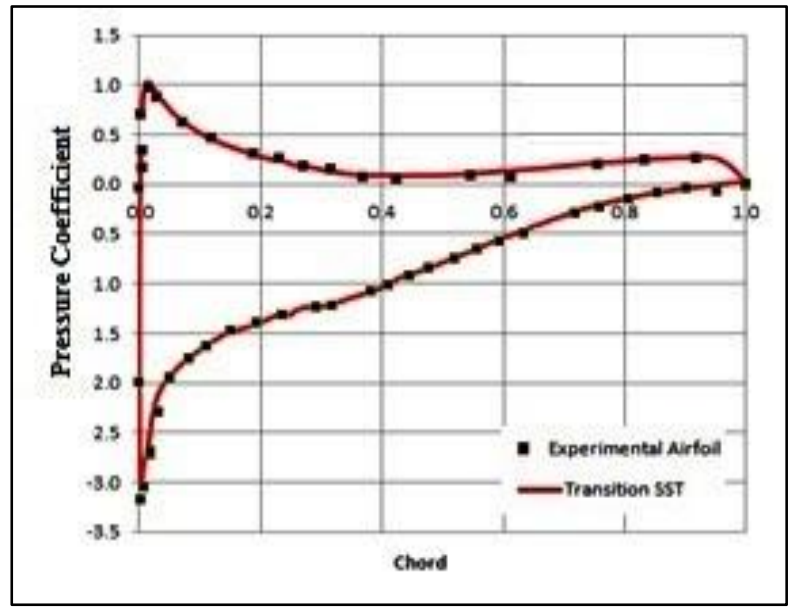

Figure 6 Validation of Pressure Coefficient at AOA $8^{\circ}$

Figure 7 and 8 present the velocity vectors for the simulated airfoil in the clean conditions at angles of attack $2^{\circ}$ and $10^{\circ}$ respectively. These figures showed that airfoil had a large velocity gradient around the front surface, indicated that curvature of airfoil's front edge accelerated the flow. Also, the flow velocity gradient of the airfoil increases with the increase of the angle of attack.
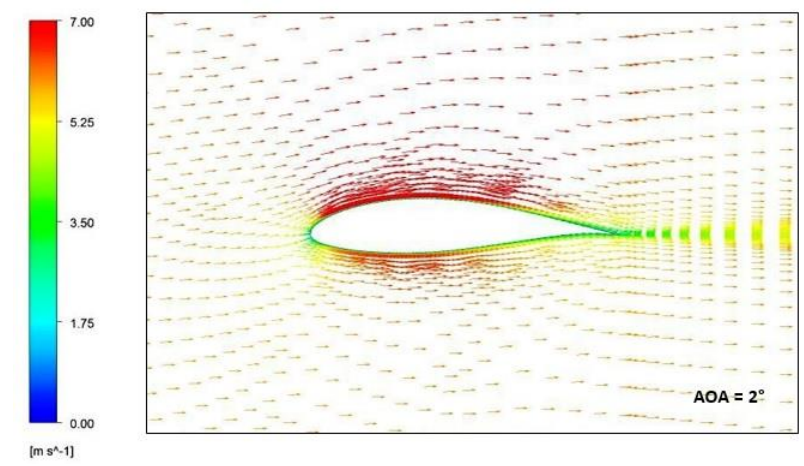

Figure 7 Velocity Vectors at AOA $2^{\circ}$

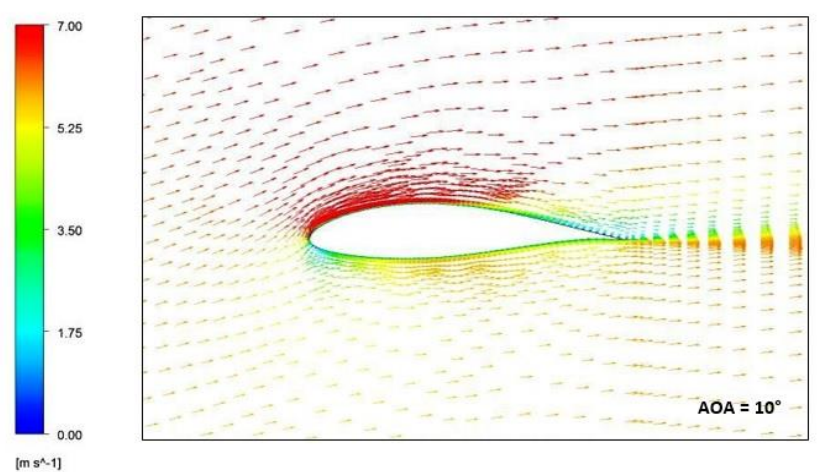

Figure 8 Velocity Vectors at AOA $10^{\circ}$ 


\subsection{Numerical Simulation under Sandy Conditions}

After validating the 2D steady incompressible Transition SST model with the experimental data in the clean condition, Discrete Phase Model was enabled to study the aerodynamic properties change of NACA 63415 in the sandy environment. The diameter of the sand particles $\left(d_{p}\right)$ in this study was chosen to be $250 \mu \mathrm{m}$ according to cases studied in the Gulf and South African countries to determine the sand particles diameter[14, 15]. The sand particle density was $2500 \mathrm{~kg} / \mathrm{m}^{3}$ and the characteristic ratio between the sand and air $(\alpha)$ in the multi-phase flow study were 0.0059 and 0.024 which represents both extremes the light and heavy sand storms. The characteristic ratio between the sand and air $(\alpha)$ were calculated through

$\alpha=\frac{\text { Volumetric Flow Rate of Sand }}{\text { Volumetric Flow Rate of Air }}$

The pressure coefficient $\left(C_{p}\right)$ distribution through the chord length of the airfoil in both clean and sandy environments has been investigated and compared. In addition, the lift coefficient $\left(C_{l}\right)$ was evaluated and studied before and after adding the sand particles effect. The angles of attack range was between $0^{\circ}$ and $10^{\circ}$ and the Reynolds number is $460 \times 10^{3}$

The dimensionless pressure coefficient $\left(C_{p}\right)$ and lift coefficient $\left(C_{l}\right)$ are:

$C_{p}=\left(P-P_{\infty}\right) /\left(0.5 \rho_{\infty} U_{\infty}^{2}\right)$

$C_{l}=L /\left(0.5 \rho_{\infty} U_{\infty}^{2} c\right)$

where $\rho_{\infty}, U_{\infty}, P_{\infty}, L, \mathrm{D}$ and $c$ are free stream density, velocity, pressure, lift force suffered by airfoil, drag force suffered by airfoil and chord length respectively.

\subsubsection{Effect of Sand Particles on Pressure Coefficient $\left(C_{p}\right)$}

Firstly, the airfoil was simulated at clean condition determining the pressure distribution through the airfoil. As seen in figures 9,10 and 11 the pressure coefficient was negative in value for the suction side of the airfoil, while the pressure coefficient was positive in the pressure side. In addition, the pressure coefficient difference between the suction and pressure sides of the airfoil is maximized at the leading edge and minimized at the trailing edge. This indicates the main role played by the leading edge in the aerodynamic performance of the airfoil. Moreover, as the angle of attack increases the pressure coefficient difference at the leading edge increases producing higher lift force at the pressure center of the airfoil.

Secondly, the discrete phase modeling was enabled and the sand particles were injected through the airfoil. After simulating the multi-phase flow of NACA 63415, it was observed that the pressure distribution over the pressure side of the airfoil was almost the same for both the clean and rough conditions. On the other hand, the pressure distribution over the suction side of the airfoil increased. This is due to the change of the flow regime which became more turbulent with the introduction of the sand particles. As the characteristic ratio between the sand and air $(\alpha)$ increases, the pressure coefficient over the suction side of the airfoil surface increases. Consequently, the pressure difference between the both sides of the airfoil decreases which affects the aerodynamic performance negatively. The aerodynamic performance degradation due to sand particles was significant at the leading edge. This degradation decreases as the chord length location through the airfoil increases. 


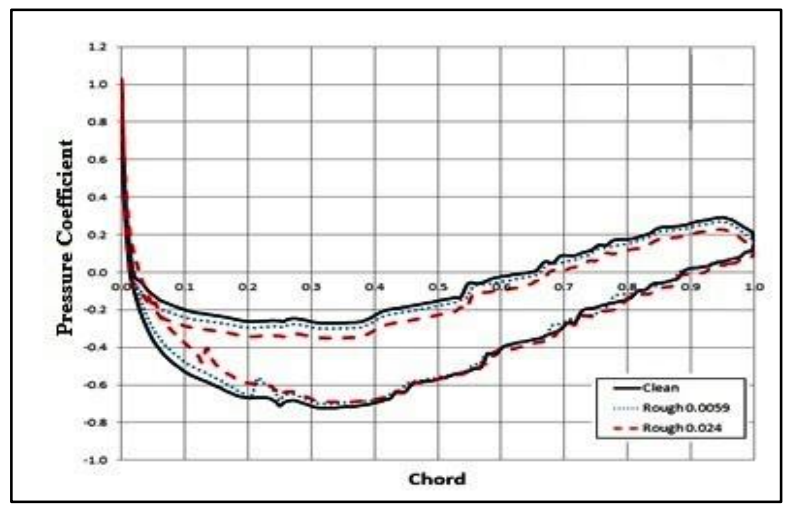

Figure 9 Pressure Coefficient Distributions along the Chord Length at $A O A 0^{\circ}$ in Clean and Sand Conditions

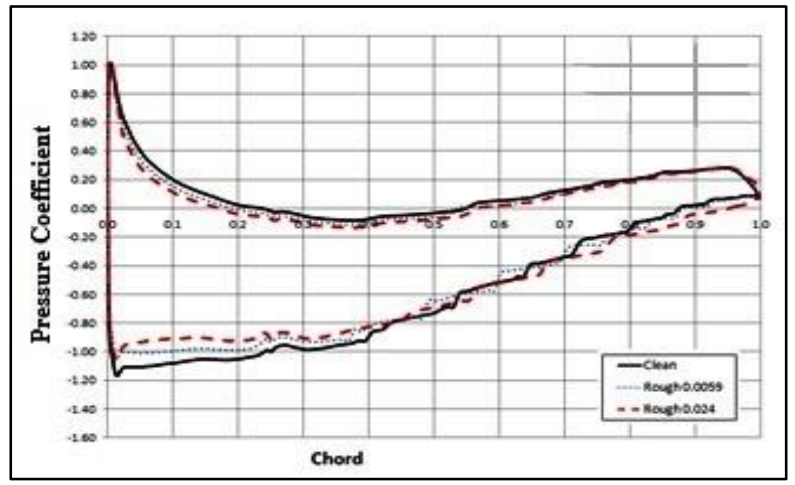

Figure 10 Pressure Coefficient Distributions along the Chord Length at AOA $4^{\circ}$ in Clean and Sand Conditions

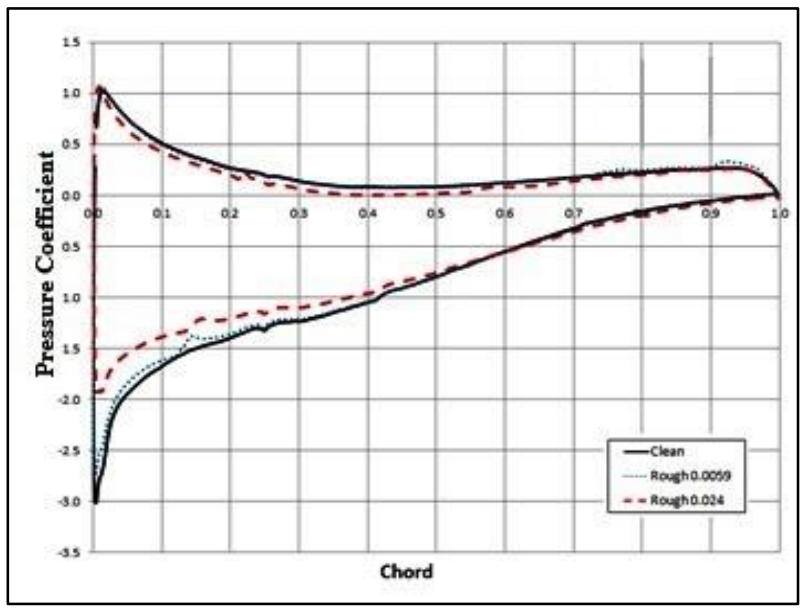

Figure 11 Pressure Coefficient Distributions along the Chord Length at AOA $8^{\circ}$ in Clean and Sand Conditions

\subsubsection{Effect of Sand Particles on Lift Coefficient $\left(\mathrm{C}_{\mathrm{l}}\right)$}

As discussed previously, the lift coefficient is induced due to the pressure difference between the two sides of the airfoil. Also, this pressure difference increases with the increase of the angle of attack, hence 
the lift coefficient increases. This is shown in figure 12. The lift coefficient increases with the angle of attack increase in both the clean and rough conditions.

In contrast, as the amount of sand flow rate increases by increasing the characteristic ratio between the sand and air $(\alpha)$, the lift coefficient of the airfoil decreases due to the reduction of the pressure difference. Figure 13 presents the lift coefficient percentage decrease at $\alpha=0.0059$ and 0.024 for angle of attack range between $0^{\circ}$ and $10^{\circ}$. It was remarked that sand particles or the multi phase flow could cause a sever loss in the airfoil performance. The percentage drop could reach up to 28 . The average percentage drop of the lift coefficient at $\alpha=0.0059$ and 0.024 was 6.5 and 18 respectively.

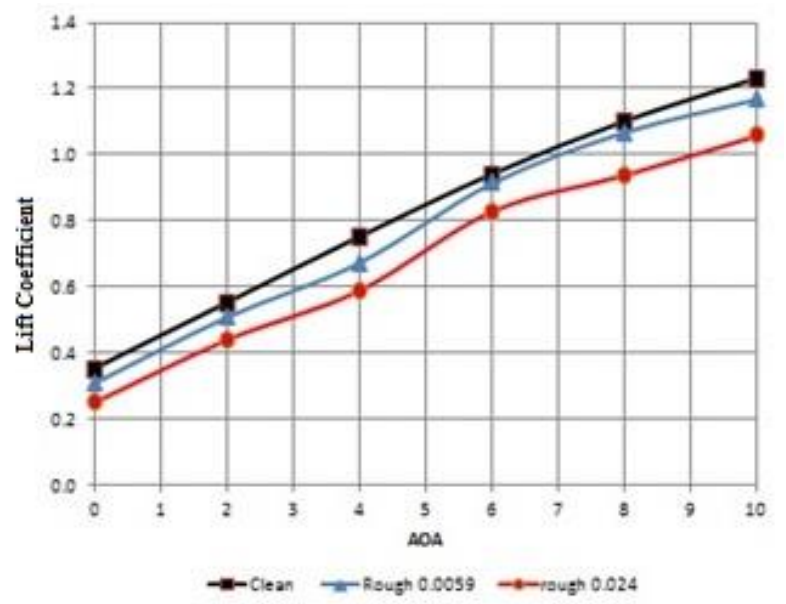

Figure 12 Lift Coefficient Vs AOA in Clean and Sand Conditions

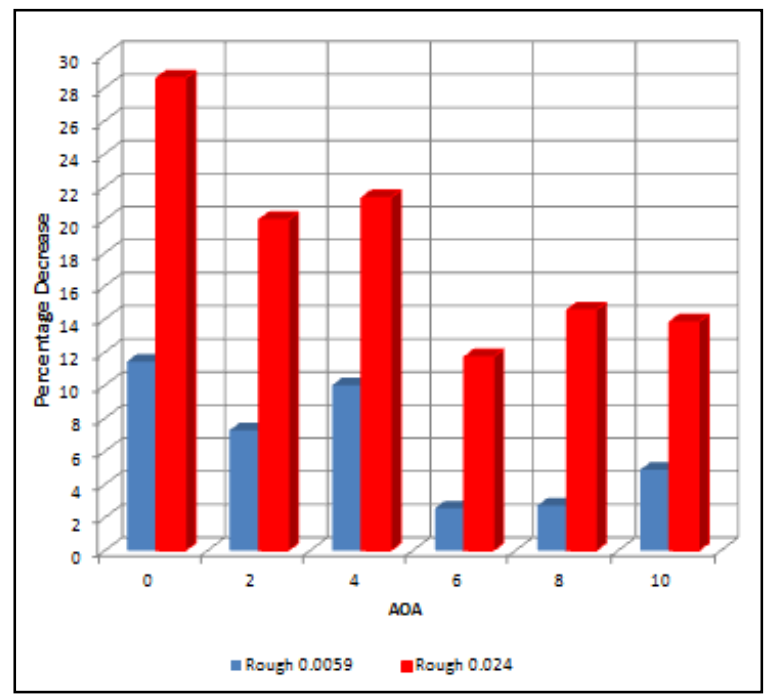

Figure 13 Lift Coefficient Percentage Decrease Vs AOA due to Sand Particles

\subsection{Conclusion}

In this paper, the RANS two-dimensional Navier-Stokes algorithm and the Transition SST turbulence model were used to investigate incompressible viscous flow past the wind turbine NACA 63415 airfoil under clean and roughness surface conditions. Firstly, the mesh sensitivity was checked and the numerical simulation under a clean airfoil surface condition was made to compare with the experimental data to ensure that the numerical model is suitable for the free-stream flow past the airfoil. Secondly, multi-phase flow of NACA 63415 airfoil was introduced using discrete phase modeling. The characteristic 
ratio between the sand and air $(\alpha)$ were 0.0059 and 0.024 which represents both extremes the light and heavy sand storms. The aerodynamic performance in both clean and sandy environments have been investigated and compared. The numerical simulation of the airfoil was performed at Reynolds number $460 \times 10^{3}$ at angle of attack range between $0^{\circ}$ and $10^{\circ}$. Results showed that sand particles hitting the airfoil could cause a sever loss in the aerodynamic performance. The percentage drop of the lift coefficient could reach up to 28. The average percentage drop of the lift coefficient at $\alpha=0.0059$ and 0.024 was 6.5 and 18 respectively.

\section{Acknowledgement}

The first author acknowledges the financial support from the Arab Academy for Science, Technology and Maritime Transport.

\section{References}

[1] Mostafa Abdel-Geliel, I.F.Z., Mohammed Anany,Sohair F. Rezeka, Modeling and Simulation of a Hybrid Power Generation System of Wind turbine, Micro-turbine and Solar Heater Cells, in 11th IEEE International Conference on Control \& Automation (ICCA). 2014: Taichung, Taiwan.

[2] Zidane, I.F., et al., On the role of surface roughness in the aerodynamic performance and energy conversion of horizontal wind turbine blades: a review. International Journal of Energy Research, 2016: p. n/a-n/a.

[3] Deshun Li, R.L., Congxin Yang, Xiuyong Wang, Effects of Surface Roughness on Aerodynamic Performance of a Wind Turbine Airfoil, in Power and Energy Engineering Conference (APPEEC). 2010.

[4] Nianxin Ren, J.O., Numerical Dust Effect on the Performance of Wind Turbine Airfoils. Electromagnetic analysis and Applications, 2009. 1: p. 102-107.

[5] Hassan Salem, A.D., Zakaria Ghoneim, CFD Simulation and Analysis of Performance Degradation of Wind Turbine Blades in Dusty Environments, in Power and Energy Engineering Conference (APPEEC). 2013: Madrid, Spain.

[6] Mohammed G. Khalfallah, A.M.K., Effect of dust on the performance of wind turbines. Desalination, 2007. 209: p. 209-220.

[7] Esteban Ferrer, X., CFD predictions of transition and distributed roughness over a wind turbine airfoil, in 47th AIAA Aerospace Sciences Meeting Including The New Horizons Forum and Aerospace Exposition. 2009: Orlando, Florida.

[8] Launder, B.E. and D. Spalding, The numerical computation of turbulent flows. Computer methods in applied mechanics and engineering, 1974. 3(2): p. 269-289.

[9] Yakhot, V., et al., Development of turbulence models for shear flows by a double expansion technique. Physics of Fluids A, 1992. 4(7): p. 1510-1520.

[10] Menter, F.R., Zonal two equation k-turbulence models for aerodynamic flows. AIAA paper, 1993. 2906: p. 1993.

[11] Dančová, P., et al., Comparison of several models of the laminar/turbulent transition. EPJ Web of Conferences, 2013. 45: p. 01032.

[12] ANSYS FLUENT Theory Guide 2011.

[13] Christian Bak, P.F., Jeppe Johansen, loannis and Antoniou, Wind Tunnel Tests of NACA 63-415 and a Modified NACA 63-415 Airfoil. Risø National Laboratory, Roskilde, Denmark, December 2000.

[14] T. Mahdaoui, N.B., M. A. Madjoubi, C. Bousbaa, Study of the Effects of Sand Blasting on Soda Lime Glass Erosion. INTERNATIONAL REVIEW OF MECHANICAL ENGINEERING, 2007. 1: p. 502510.

[15] Henley, P., Unpublished soil sample report, Remote Sensing Division, Resewcl Institute, U.S. Army Engineer Topographic Laboratories, Ft Belvoir, VA,. 21 Nov 90. 